\title{
Predictive Value of Helix Pomatia Agglutinin (HPA) Lectin in Management of Complete Hydatidiform Mole
}

\author{
Ziba Shokri ${ }^{1}$, Fatemeh Atabaki Pasdar*1, Haleh Ayatollahi², Siamak Naji ${ }^{3}$, Gholam Hossein Farjah ${ }^{4}$, \\ Khadije Meghrazi ${ }^{1}$
}

1. Department of Anatomical Sciences, Faculty of Medicine, Urmia University of Medical Sciences, Urmia, Iran

2. Department of Gynecology \& Obstetrics, Motahari Hospital, Urmia University of Medical Sciences, Urmia, Iran

3. Department of Pathology, Motahari Hospital, Urmia University of Medical Sciences, Urmia, Iran

4. Neurophysiology Research Center, Department of Anatomical Sciences, Faculty of Medicine, Urmia University of Medical Sciences, Urmia, Iran

\begin{abstract}
Background and objectives: Hydatidiform mole is the most common form of gestational trophoblastic disease, which originates from the placenta and is categorized into complete and partial hydatidiform moles. About 10-30\% of complete hydatidiform moles (CHMs) might develop into persistent trophoblastic disease. Helix pomatia agglutinin (HPA) lectin has been suggested as a marker of alteration of glycosylation in human malignancies. The aim of this study was to determine efficacy of HPA lectin as a prognostic indicator for clinical behavior of CHMs.

Methods: Lectin histochemistry with biotin-conjugated HPA lectin was performed on paraffin sections of CHM tissues from 24 patients with progression to persistent trophoblastic disease (case group) and 24 patients with spontaneous regression (control group). The sections were graded according to lectin staining intensity (0-3) and the percentage of cell reactions was evaluated based on the staining grades.

Results: HPA lectin showed a mild to moderate reactivity with syncytiotrophoblasts, which was most evident in apical portion, but did not react with cytotrophoblasts and stromal cells. The mean staining intensity values did not differ significantly between the two groups ( $\mathrm{P}=0.447)$.

Conclusion: Based on the results, HPA lectin is not a good prognostic indicator for clinical behavior of CHMs.
\end{abstract}

KEYWORDS: Complete Hydatidiform mole, Lectin, Histochemistry, HPA

Received: 2018/12/17

Revised:2018/12/30

Published:2019/01/01

*Correspondence: Fatemeh Atabaki Pasdar

Address: Department of Anatomical Sciences, Faculty of Medicine, Urmia University of Medical Sciences, Pardis Nazloo- 11th Km of Sero (Nazloo) Road, Urmia, Iran

Telephone: +98-4432770698 Email: atabaki_f@umsu.ac.ir 


\section{INTRODUCTION}

Gestational trophoblastic disease (GTD) refers to a group of diseases ranging from abnormal proliferation of placental trophoblasts with varying tendencies for local invasion and metastases to hydatidiform mole (HM) and non-molar trophoblastic diseases (1). As the most common form of GTD, partial HM and particularly complete HM (CHM) is associated with increased risk of developing persistent trophoblastic disease or gestational trophoblastic neoplasia (GTN) $(2$, 3). GTN refers to a group of uncommon malignant gynecological tumors that arise from trophoblastic cells including invasive moles, choriocarcinoma, placental site trophoblastic tumors, and epithelioid trophoblastic tumors (4).

Predicting the risk of $\mathrm{CHM}$ progression to persistent GTD is of great importance. The current reliable method of diagnosing persistent GTD relies on detection of persisting or rising postmolar $\beta$-human chorionic gonadotropin ( $\beta$-hCG) levels. After evacuation of mole, $\beta$-hCG level is closely monitored at least every two weeks. Diagnosis of GTN is made based on an elevated or rising hCG titers over a period of several weeks (5), but these values cannot predict the outcome of HM immediately after the evacuation. Determining whether HM could be malignant at the time of its initial diagnosis could prevent the complications associated with advanced malignancy (6). Thus, researchers are seeking for markers capable of predicting malignant transformation of HMs immediately after the evacuation. There have been several studies on the use of lectin histochemistry and immunohistochemistry in differential diagnosis of HMs (7-9), but few studies have investigated the prognostic value of these methods, particularly lectin histochemical methods, for HMs.

It is widely accepted that altered glycosylation of cell surface glycoproteins accompanies malignant transformation (10). Overexpression of $\mathrm{N}$-acetylgalactosamine (GalNAc) oligosaccharides is one of the most common glycosylation alterations seen in malignancy (11). This overexpression can be detected using the lectin Helix pomatia agglutinin (HPA), a prognostic marker for several human cancers, including breast $(12,13)$, stomach $(14,15)$, colon $(16,17)$, and prostate (18) cancer. The aim of this study was to determine efficacy of HPA lectin as a prognostic indicator for clinical behavior of CHMs.

\section{MATERIAL AND METHODS}

Sample preparation

Records and follow-up data of patients diagnosed with CHM were obtained from the oncology clinic of Motahary hospital in Urmia, Iran. After reviewing the records, 24 patients with persistent trophoblastic disease after CHM (case group) and 24 patients with spontaneous regression (control group) were enrolled. Paraffin blocks of all subjects were collected and cut into 4-5 $\mu \mathrm{m}$ thick serial sections. Some sections were randomly stained with hematoxylin-eosin and histopathologically reviewed by a pathologist for confirmation of diagnosis. The most suitable area for lectin histochemistry was determined. The samples with inadequate or necrotic tissues were excluded from this study. The selected sections were deparaffinized in xylene and rehydrated by passing through graded dilutions of ethanol. Endogenous peroxidase activity was inhibited by pre-incubation of tissues with $0.5 \%$ hydrogen peroxide in methanol for 15 minutes at room temperature. After washing with phosphate buffer saline (PBS), tissue sections were covered with biotin conjugated HPA lectin (Sigma-Aldrich Co.) diluted in $0.1 \mathrm{M}$ PBS to reach a final concentration of 10 $\mu \mathrm{g} / \mathrm{ml}$ of lectin. The sections were placed in a humid chamber for 2 hours at room temperature. Excess unbound reagent was removed by three times washing with PBS, and then streptavidin- horseradish peroxidase (Dako) was applied to the sections for one hour. After a final wash with PBS, the reaction was visualized by using $0.03 \%$ 
solution of diaminobenzidine. The slides were counterstained with hematoxylin. Negative

control samples were prepared using the same procedures without lectin (19).

Three sections for each sample and five fields for each section were examined under a light microscope (at 200X magnification). The staining intensity was graded in an observerblind manner and scored using a four-point staining intensity scale (0-3): $3+++$ : strong reactivity, $2++$ : moderate reactivity, $1+$ : mild (weak) reactivity, and 0 : no reactivity (negative) (20). For each section, the mean staining intensity was calculated using the following formula:

Mean staining intensity $=0 \times$ (proportion of negative) $+1 \times$ (proportion of $1+)+2 \times$ (proportion of $2+$ ) $+3 \times$ (proportion of $3+$ ) (21).

\section{Statistical analysis}

Collected data were analyzed by the MannWhitney U test. P-values less than 0.05 were considered as statistically significant.

\section{RESULTS}

Reactivity with HPA was assessed in villous cytotrophoblasts, syncytiotrophoblasts, and core stromal cells. Lectin that recognizes terminal alpha-GalNAc showed a weak to moderate reactivity with syncytiotrophoblasts in both groups, which was most evident in apical portion, but did not react with cytotrophoblasts and stromal cells. No strong reactivity was observed in the study groups (Figure 1a-c). There was no significant difference in the percentage of cell reactions between the study groups based on the histochemical grading (Table 1). Furthermore, the mean staining intensity values did not differ significantly between the two groups (Table 2).
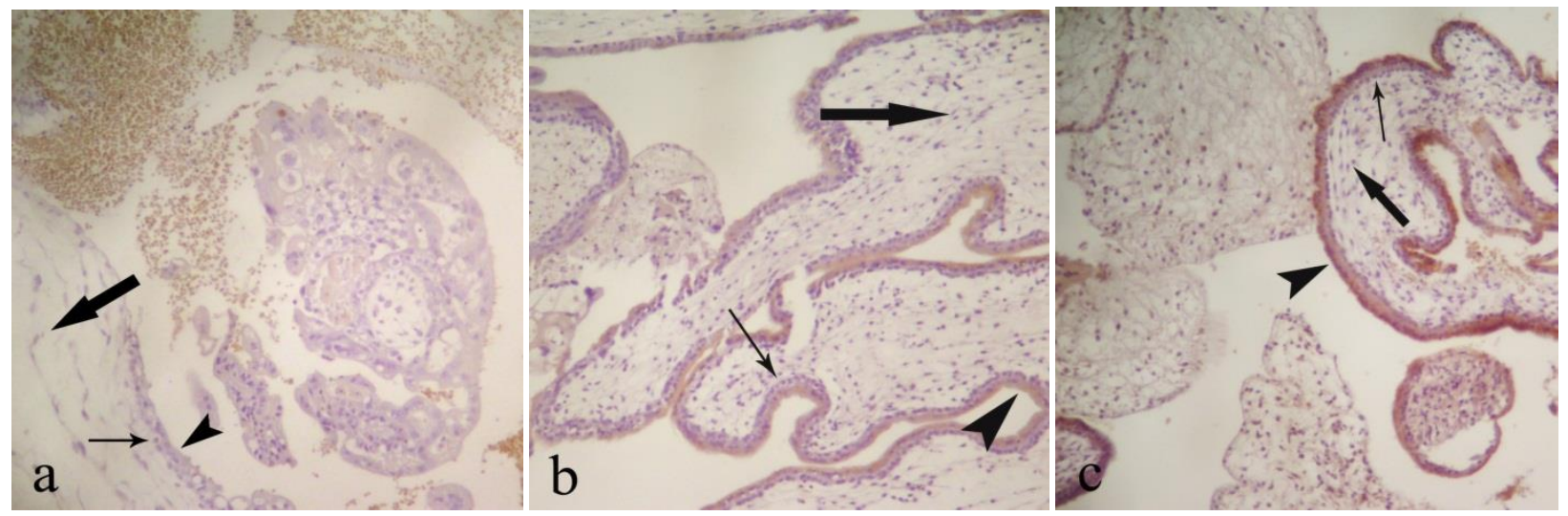

Figure1. Reactivity with HPA in villous cytotrophoblasts, syncytiotrophoblasts, and core stromal cells. a: No reactivity with HPA in cytotrophoblasts (small arrow), syncytiotrophoblasts (arrow head), and stromal cells (large arrow) in the control group, erythrocytes serve as internal positive control, b: weak reactivity with HPA in syncytiotrophoblasts (arrow head) and no reactivity in cytotrophoblasts (small arrow) and stromal cells (large arrow) in the control group, c: Moderate reactivity with HPA in syncytiotrophoblasts, which was more evident in the apical portion (arrow head) and no reactivity in cytotrophoblasts (small arrow) and stromal cells (large arrow) in the case group. All images were taken under X200 magnification. 
Table 1. Percentage of cell reactions in both groups according to histochemical grading

\begin{tabular}{|c|c|c|c|c|}
\hline Hroups & No reactivity & Mild reactivity & Moderate reactivity & Strong reactivity \\
\hline Regressive & $72.92 \pm 32.635$ & $22.50 \pm 28.014$ & $4.58 \pm 17.189$ & 0 \\
\hline Progressive & $65.42 \pm 35.506$ & $29.17 \pm 30.060$ & $5.42 \pm 18.645$ & 0 \\
\hline P-value & 0.450 & 0.431 & 0.873 & - \\
\hline
\end{tabular}

Results are expressed as mean \pm standard deviation

Table 2. Mean staining intensity in the case (progressive) and control (regressive) groups

\begin{tabular}{|l|c|c|c|}
\hline Gariable & Regressive group & Progressive group & P-value \\
\hline Mean staining intensity & $0.3167 \pm 0.44003$ & $0.4000 \pm 0.48094$ & 0.447 \\
\hline
\end{tabular}

Results are expressed as mean \pm standard deviation

\section{DISCUSSION}

About half of GTN cases develop following molar pregnancy (22), and $10-30 \%$ of women with CHM progress to persistent trophoblastic disease or GTN (3). In Asia, CHM is seven to ten times more common than in western countries (23). There is currently no reliable marker available besides serum $\beta$-hCG to identify progression of molar pregnancies to GTN. However, assessment of serum $\beta$-hCG can be time-consuming, costly, and a burden for patients (24). Expression of HPA binding glycoproteins by primary tumor cells seems to be good marker of poor patient prognosis (1218). In the present study, we evaluated the prognostic value of this marker in CHM. Our results indicate that HPA reacts differently with various components of $\mathrm{CHM}$ tissue. Lectin exhibited a mild to moderate reactivity with syncytiotrophoblasts in both groups, which was more evident in the apical portion, but did not react with cytotrophoblasts and stromal cells. Cytotrophoblast is the trophoblastic stem cell, whereas syncytiotrophoblast is the terminally Differentiated cell that produces most of the placental hormones (25). The apical portion of the syncytiotrophoblast corresponds to the microvillus brush border that has been shown to be highly glycosylated $(26,27)$. To our knowledge, this study is the first to evaluate expression of HPA in molar placental tissues. However, Lee et al. reported that HPA does not react with any components of normal placenta including villous cytotrophoblasts, syncytiotrophoblasts and core stromal cells (28).

We found no significant difference in the mean staining intensity between CHMs progressing to persistent GTDs and those in spontaneous remission. These results could be due to technical reasons or to the fact that molar tissues behave differently with respect to HPA binding compared to other tumors (breast, colon, prostate and gastric cancers) 
(13-18). Technical differences in the methods used in studies could lead to false negative results concerning the prognostic value of HPA (29). For instance, even though many studies have reported that HPA is of prognostic value in breast cancer using the indirect immunoperoxidase method, two studies claimed the opposite by using a less sensitive method (30,31). In addition, this inconsistency may be due to their different histogenic origin. Similar to our findings, other studies reported that HPA is not of prognostic value in squamous cell carcinomas of the upper aerodigestive tract $(32,33)$. As mentioned previously, HM originates from the placenta, which comprises specialized epithelial cells that arise from the trophectoderm of the blastocyst, the epithelium-like layer surrounding the early embryoblast (34). HPA binding may be of biological significance only in tumors of glandular origin (32).

\section{CONCLUSION}

Based on the results, HPA lectin is not a good prognostic indicator for clinical behavior of CHMs.

\section{ACKNOWLEDGMENTS}

We would like to express our sincere gratitude to the Vice Chancellor for Research at Urmia University of Medical Sciences for supporting this study. We also wish to thank Mrs. Tasbihforoush for her kind assistance in clinical data collection.

\section{DECLARATIONS \\ Funding}

This study was financially supported by the Urmia University of Medical Sciences, Iran (project number: 1393-04-32-1383).

\section{Ethics approvals and consent to participate}

The study received approval from the Research Ethics Committee of Urmia University of Medical Sciences (code: IR.UMSU.REC.1393.146).

\section{CONFLICT OF INTEREST}

The authors declare that there is no conflict of interest.

\section{REFERENCES}

1- Niemann I, Vejerslev L, Froding L, et al. Gestational Trophoblastic Diseases, Clinical guidelines for diagnosis, treatment, follow-up, and counseling. Danish Med J. 2015; 62(11): 119.

2- Alhamdan D, Bignardi T, Condous G. Recognising gestational trophoblastic disease. Best Pract Res Clin Obstet Gynaecol. 2009; 23(4):565-73.

https://doi.org/10.1016/j.bpobgyn.2009.03.001

3- LeGallo RD, Stelow EB, Ramirez NC, Atkins KA. Diagnosis of hydatidiform moles using p57 immunohistochemistry and HER2 fluorescent in situ hybridization. Am J Clin Pathol. 2008; 129(5):749-55.

https://doi.org/10.1309/7XRL378C22W7APBT

4- Berkowitz RS, Goldstein DP. Current advances in the management of gestational trophoblastic disease. Gynecol Oncol. 2013; 128(1):3-5.

https://doi.org/10.1016/j.ygyno.2012.07.116

5- Ngan HYS, Kohorn EI, Cole LA, Kurman RJ, , Kim SJ, Lurain JR, et al. Trophoblastic disease. International Journal of Gynecology and Obstetrics.2012;119:130-136.

https://doi.org/10.1016/S0020-7292(12)60026-5

6- Hegab HM, Schindler AE. The prognostic value of serum inhibin, 17 beta- estradiol and progestrone in cases of hydatidiform mole. GynecolEndocrinol.2004;18(2):107-13. https://doi.org/10.1080/09513590310001652991

7- Kubelka-Sabit KB, Prodanova I, Jasar D, et al. Molecular and Immunohistochemical Characteristics of Complete Hydatidiform Moles. Balkan J Med Genet. 2017; 20(1): 27-34. https://doi.org/10.1515/bjmg-2017-0009

8- Atabaki Pasdar F, Khooei A, Fazel A, Mahmoudi M, Nikravesh MR, Khaje Delui M. Diagnostic value of lectins in differentiation of molar placentas. Iran J Basic Med Sci. 2012; 
15(6): 1140-7.

9- Samadder A, Kar R. Utility of p57 immunohistochemistry in differentiating between complete mole, partial mole \& non-molar or hydropic abortus. Indian J Med Res. 2017; 145(1):133-137.

https://doi.org/10.4103/ijmr.IJMR_982_15

10- Rambaruth ND1, Greenwell P, Dwek MV. The lectin Helix pomatia agglutinin recognizes O-GlcNAc containing glycoproteins in human breast cancer. Glycobiology. 2012; 22(6): 83948.

https://doi.org/10.1093/glycob/cws051

11- Brooks SA, Leathem AJ, Camplejohn RS, Gregory W. Markers of prognosis in breast cancer--the relationship between binding of the lectin HPA and histological grade, SPF, and ploidy. Breast Cancer Res Treat. 1993; 25(3): 247-56.

https://doi.org/10.1007/BF00689839

12- Welinder C, Jansson B, Ferno M, Olson H, Baldetorp B. Expression of Helix Pomatia Lectin Binding Glycoproteins in women with breast cancer in relationship to their blood group. J ProteomeRes.2009;8(2):782-7.

https://doi.org/10.1021/pr800444b

13- Brooks SA. The involvement of Helix pomatia lectin (HPA) binding $\mathrm{N}$ acetylgalactosamine glycans in cancer progression. Histol Histopathol 2000; 15(1): 143158.

14- Kakeji Y, Tsujitani S, Mori M, Maehara Y, Sugimachi K. Helix pomatia agglutinin binding activity is a predictor of survival time for patients with gastric carcinoma. Cancer 1991; 68: 24382442.

https://doi.org/10.1002/10970142(19911201)68:11<2438::AIDCNCR2820681119>3.0.CO;2-\#

15- Arab MR, Salari S, Karimi M, Mofidpour H. Lectin histochemical study of cell surface glycoconjugate in gastric carcinoma using helix pomatia agglutinin. Acta Med Iran. 2010; 48(4): 209-13.
16- Saint-Guirons J, Zeqiraj E, Schumacher U, Greenwell P, Dwek M. Proteome analysis of metastatic colorectal cancer cells recognized by the lectin Helix pomatia agglutinin (HPA). Proteomics. 2007; 7(22): 4082-4089. https://doi.org/10.1002/pmic.200700434

17- Schumacher U, Higgs D, Loizidou M, Pickering R, Leathem A, Taylor I. Helix pomatia agglutinin binding is a useful prognostic indicator in colorectal carcinoma. Cancer. 1994; 74: 31043107.

https://doi.org/10.1002/1097-

0142(19941215)74:12<3104::AID-

CNCR2820741207>3.0.CO;2-0

18- Shiraishi T, Atsumi S, Yatani R. Comparative study of prostatic carcinoma bone metastasis among Japanese in Japan and Japanese Americans and whites in Hawaii. Adv Exp Med Biol.1992;324:7-16.

https://doi.org/10.1007/978-1-4615-3398-6_2

19- Thower S, Bulmer JN. Further studies of lectin binding by villous and extravillous trophoblast in normal and pathological pregnancy. Int J Gynecol Pathol. 1991; 10(3): 238-251.

https://doi.org/10.1097/00004347-199107000$\underline{00003}$

20- Arab M, Sepehri Z, Eimani H, Karimi M, Sargolzaie F. Histochemical Study of Nacetylgalactosamine Containing Glycoconjugate in Intraductal Carcinoma of the Breast by HPA Lectin. Yakhteh Med J. 2006; 7(4): 216-221.

21- Korourian S, Siegel E, Kieber-Emmons T, Monzavi-Karbassi B. Expression analysis of carbohydrate antigens in ductal carcinoma in situ of the breast by lectin histochemistry. BMC Cancer. 2008; 14; 8:136.

22- Ngan HYS, Seckl MJ, Berkowitz RS, Xiang Y, Golfier F, Sekharan PK, et al. Trophoblastic disease. International Journal of Gynecology and Obstetrics.2015;131:123-126. https://doi.org/10.1016/j.ijgo.2015.06.008

23- Horn LC, Kowalzik J, Bilek K, Richter CE, 
Einekel J. Prognostic value of trophoblastic proliferation in complete hydatidiform moles in predicting persistent diseases. Pathol Res \& Pract.2006(202):151156.

https://doi.org/10.1016/j.prp.2005.11.009

24- Bae SN, Kim SJ. Telomerase activity in complete hydatidiform mole. Am J Obstet Gynecol. 1998; 180(2): 328-333. https://doi.org/10.1016/S0002-9378(99)70208-5

25- Shih IM, Kurman RJ. The pathology of intermediate trophoblastic tumors and tumor-like lesions. Int J Gynecol Pathol. 2001; 20(1): 31-47. https://doi.org/10.1097/00004347-200101000$\underline{00004}$

26- Jones CJ, Dantzer V, Leiser R, Krebs C, Stoddart RW. Localisation of glycans in the placenta: a comparative study of epitheliochorial, endotheliochorial, and haemomonochorial placentation. Microsc Res Tech. 1997; 38(1-2): 100-14. https://doi.org/10.1002/(SICI)10970029(19970701/15)38:1/2<100::AIDJEMT11>3.0.CO;2-T

27- Whyte A. Lectin binding by microvillous membranes and coated-pit regions of human syncytial trophoblast. Histochem J. 1980; 12(5): 599-607. https://doi.org/10.1007/BF01011933

28- Lee MC, Damjanov I. Lectin histochemistry of human placenta. Differentiation. 1984; 28(2): 123-8.

https://doi.org/10.1111/j.1432-

$\underline{0436.1984 . t b 00275 . x}$

29- Brooks SA, Lymborus M,Schumacher U, Leathem AJ . Histochemistry to detect Helix Pomatia lectin in Breast Cancer: methodology makes a differences. J Histochem Cytochem. 1996;44:519-24.

https://doi.org/10.1177/44.5.8627008

30- Gusterson BA. Prognostic Value of Helix Pomatia in Breast Cancer. $\mathrm{Br} \mathrm{J}$ Cancer 1993;68:146-50.

https://doi.org/10.1038/bjc.1993.303
31- Taylor CW, Anbazhagan R, Jayatilake H, et al. Helix Pomatia in Breast Cancer. Lancet. 1991; 338:580-584.

https://doi.org/10.1016/0140-6736(91)91154-M

32- Schumacher DU, Randall CJ, Ramsay AD, Schumacher U. Is the binding of the lectin Helix pomatia agglutinin (HPA) of prognostic relevance in tumours of the upper aerodigestive tract? Eur J Surg Oncol. 1996; 22(6): 618-20. https://doi.org/10.1016/S0748-7983(96)92424-5

33- Yoshida Y, Okamura T, Yano K, Taga S, Ezaki T. Histopathological characteristics associated with long-term survival in stage III esophageal carcinoma. Cancer. 1994; 7: 147-9.

34- Gauster M1, Blaschitz A, Siwetz M, Huppertz B. Keratins in the human trophoblast. Histol Histopathol. 2013; 28(7): 817-25. 